\title{
Themes in "Good Leadership": An Analysis of Personal Stories of Inspiration from the Daqing Oil Field
}

\author{
Michael MILES ${ }^{1, a}$, Nancy JENSTER ${ }^{1, b}$ and Mundeep GILL $^{3, c}$ \\ ${ }^{1} 55$ Laurier Avenue East, Ottawa, ON, K1N 6N5, Canada \\ ${ }^{2}$ West Wing, 103-39 Persiaran Gurney, 10250 George Town, Penang, Malaysia \\ amiles@telfer.uOttawa.ca, bmgill@alumni.uottawa.ca, cnancy.jenster@gmail.com
}

\section{Keywords: Character, Leadership, China, SOE, Petro China}

\begin{abstract}
This study explores the practice of Chinese leadership within a large Chinese StateOwned Enterprise (SOE). Seventy middle managers were asked to submit a hand-written Chineselanguage "leadership story", identifying a leader who they had experienced modeling "good leadership", the specific behavior(s) that this leader exhibited, and the situational context in which the behavior(s) had occurred. Participants were also asked to outline the cultural influences that, in their view, had influenced that behavior(s). Results show nine clusters of exemplary leadership behaviors: Caring, Respectful / Fair, Guiding / Mentoring, Professional and Technically Knowledgeable, Objectivity / Pragmatism, Leading by Example, Accountability, Visionary / Innovation, and Discipline. The study defines and summarizes these clusters and provides specific examples of leadership behavior consistent with each cluster.
\end{abstract}

\section{Introduction}

"Watch your thoughts, for they become words. Watch your words, for they become actions. Watch your actions, for they become habits. Watch your habits, for they become your character. And watch your character, for it becomes your destiny. What we think, we become. "

-Margaret Thatcher

As the world's second largest economy, China relies on a constant supply of energy to keep its engines and machines roaring and its hungry cities' lights burning brightly. Likewise, Chinese business organizations rely upon a constant supply of high quality leaders, capable of maintaining workers' productivity, motivation, and engagement. These leaders must possess the right "character" in order to inspire and motivate their followers. However what is the right "character" for a leader to possess from the Chinese perspective? How does this "character" present itself in actual leadership behaviors?

China's 5000 year-old cultural tradition, history and current challenges shape the current generation of leaders" "ideals" of "good leadership" [1]. This image is likely to be quite different from the images held by managers from other cultures, particularly Western cultures. Yet, since Deng Xiao Ping's famous speech in the South of China in 1992 extolling the virtues of becoming rich and opening up China to broader influences, Western and Chinese management researchers have transposed Western models of good leadership, as well as Western cultural "ideals" of leadership behavior, onto the landscape of Chinese business. Not surprisingly, research through Western lenses has yielded Western conceptualizations of indigenous Chinese leadership phenomena. [2] A recent trend in Chinese management research has focused on building an indigenous model of Chinese management and leadership, based upon a foundation of knowledge of Chinese historical background and cultural traditions and merging the Western and Chinese theories into a useful model for today's leaders of modern Chinese organizations. [3]

With this study, the intent is to contribute to this research space by beginning with the stories of native Chinese respondents regarding their experience of "good leadership" to inductively create a model of Chinese leadership represented by the patterns of behavior nominated by the study participants themselves. The research investigates the construct of "good Chinese leadership" 
directly through the eyes of Chinese State-Owned Enterprise (SOE) managers. Within the cultural and environmental context as noted by our respondents, building upon observations made by other scholars of Chinese management, we aim to contribute to the growing body of field research on leadership in a purely indigenous Chinese context through grounded research methods.

\section{Theoretical Background}

\section{Leadership and Character}

Within the context of organizational theory, leadership represents a core managerial construct. [4] The degree to which it has been researched and analyzed in the Western literature reflects the assumptions assigned to the significance of leadership behavior related to business success. [5] Much of this research has focused on the behaviors of effective leadership, i.e. what leaders do. While this has led to the redesign of leadership training programs, observers of Western business practice have at times noted inconsistencies between leaders' behaviors and their values. As Fernandez notes, "one can adjust one's behavior to what is expected, but one's actions many not be the true reflection of one's convictions and preferences." [6] In the West, as in China, business leaders are increasingly concerned by the lack of focus on the "character strength" of their leaders, the deficits of which have led to many cases of scandalously unethical behavior on the part of business leaders. The unethical behavior of business leaders in the West has led to a "crisis of confidence" [7] and to a questioning of how we develop the desired "character" attributes of our leaders, as opposed to looking solely at what "behaviors" should be exhibited by an effective leader. These lead us to questions related to cultural values and expected virtues that our leaders must possess in order to earn our trust and loyalty.

\section{Character and the Exemplary Chinese Leader}

When investigating the ideals of exemplary leadership character within Chinese organizations, scholars have shown that there are many diverse styles of leadership in China, ranging from "authoritative" to "invisible", according to the type of organization, the context, and the culture of the organization. [8] Most scholars also point to the need to also examine the historical roots of leadership contained in China's ancient history as well as its more recent, rapid, and evolving political influences. [9]

\section{Confucian Influences on Exemplary Leadership Character}

Confucianism has a pervasive influence on Chinese leadership. [10] "(Confucian) leadership is an emergent quality of character that radiates and makes others want to follow, based on the respect and trust the leader generates". [11] The leader (Confucian) is a "gentleman" (junzi), a person who through constant self-improvement, exhibits exemplary behavior reflecting the correct system of values and the proper character strengths. [12] Indeed, in Confucius' thinking, the idea of benevolence - renqing - based upon a belief in the fundamental goodness of man, was the most important of the virtues and formed the backbone of a Confucian theory of benevolent leadership. [13] According to this theory, the benevolent leader cultivates his own character constantly as a "wise sage", and leads others benevolently, a pattern leading to a harmonious and benevolent society of which two values form the foundation of the exemplary Confucian leader: Kindness and Justice. [14]

\section{Chinese Leadership: The Good Father}

Chinese leadership studies have also pointed to the paternalistic nature of leadership in Chinese organizations, the so-called Paternalistic Leadership Model. [15] Under this model, the leader acts as a kind and just father-figure to employees, a style combining "strong discipline and authority with fatherly benevolence and moral integrity". [16] Chen and Kao explain that the benevolent leader in China is kind and tolerant towards subordinates, expressing his/her concern for their employee's well-being, both on the job and at home. [17] In addition, paternalistic Chinese leaders 
place high value on harmony and reciprocity in all their social relationships. In addition, these leaders convey a warm sense of "human-heartedness" (renqing), granting favors to those in their care needing help, and in general, living with a considerate attitude. [18]

\section{Communist Ideological Influences}

Just as traditional Confucian precepts continue to influence Chinese leaders' behavior today, so too have the ideological precepts of Communism wielded a great impact over the past several decades. [20] The CCP Constitution describes an ideology including "whole-hearted service to the People, loyalty to the Party, hard work and self- sacrifice". [21] In addition, there are four leadership principles, "Four Goods", which are transmitted through leadership development of the SOE senior management by the Leadership Institute of the CCP. These principles are taught with the intent of having an impact on how SOE leaders act and judge others in relation to the leadership of their organizations. [22] Our review of recent research on Chinese leadership character, values, and behaviors leads us to surmise that there is a continuing influence of Confucian values as well as Communist ideological principles on Chinese perceived "good leadership".

Table 1 - Four Leadership Principles of CCP (Four Goods)

\begin{tabular}{|ll|}
\hline \multicolumn{1}{|c|}{$\begin{array}{l}\text { Goods* } \\
\text { Political }\end{array}$} & $\begin{array}{l}\text { Ensuring progress through full understanding and ownership of the CCP } \\
\text { perspectives. }\end{array}$ \\
\hline $\begin{array}{l}\text { Producing } \\
\text { Results }\end{array}$ & $\begin{array}{l}\text { Knowing and following policies, following the customer and the market, driving } \\
\text { for creative but steady development, setting clear goals, avoiding risk, and } \\
\text { striving to be the best company possible. }\end{array}$ \\
\hline $\begin{array}{l}\text { Cooperation } \\
\text { and Unity }\end{array}$ & $\begin{array}{l}\text { Knowing personal responsibilities and how each unit is interdependent - } \\
\text { emphasizing mutual respect and support }\end{array}$ \\
\hline $\begin{array}{l}\text { Role } \\
\text { Modeling }\end{array}$ & $\begin{array}{l}\text { "Walking the talk", where leaders' actions and words are consistent, hard- } \\
\text { working, and strive to help those at levels below to solve problems with an } \\
\text { emphasis on fostering strong interpersonal relationships with employees }\end{array}$ \\
\hline
\end{tabular}

\section{Study}

In this study, we have collected qualitative data in the form of stories defining "good leadership" from seventy senior and middle managers of the Daqing Petrochemical Company, a Chinese state owned enterprise (SOE). The participants were involved in a management development workshop exploring themes of leadership and management practice. Eighty percent of respondents were between 35 to 50 years of age, and held positions of management responsibility at the departmental, workshop or mid-senior level. In terms of gender, eighty-one percent of respondents were male, and most respondents' educational profile consisted of at least an undergraduate college degree.

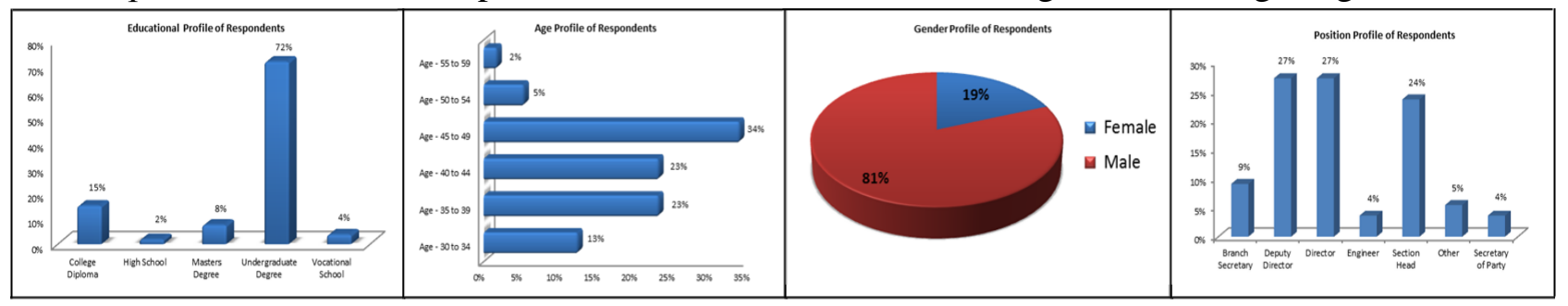

Figure 1 - Respondent Demographic Overview

\section{Results}

The survey results provide detailed insight into what behaviors are recognized as "good 
leadership" from the point of view of managers in the Daqing Petrochemical Company. The major trends emerging from the participants' stories are outlined in definition form in Table 2 below. The naming of behavioral themes are in the precise words of the participants wherever possible. The process of gathering stories from managers about their perception of good leadership has, in itself, generated some interesting insights for the research team. It is important to note that many of the behaviors observed in the stories were complementary and often arose simultaneously, as a consequence of, or as a precursor to one another. This observation simply highlights that individual behaviors are difficult to examine as independently occurring phenomenon. Behavior is the result of both the observer and the actors' combined perception, experiences, beliefs, and specific contexts. Figure 3 names the top observed behavioral leadership themes in order of highest frequency.

Table 2 - Definitions of Observed Behavioral Themes

\begin{tabular}{|ll|}
\hline Behavioural Theme & Respectful / Fair \\
$\begin{array}{l}\text { 49 References / 30 } \\
\text { Sources }\end{array}$ & $\begin{array}{l}\text { Mindful of the ideas of followers / subordinates and their sentiments, } \\
\text { trusting of subordinate opinions and expertise, open in general } \\
\text { communication with subordinates in a way that treats all equally. }\end{array}$ \\
\hline $\begin{array}{l}\text { Guiding / } \\
\text { Mentoring } \\
\text { 41 References / 27 } \\
\text { Sources }\end{array}$ & $\begin{array}{l}\text { Provides direction and advice in facilitating follower development and } \\
\text { career success. }\end{array}$ \\
\hline $\begin{array}{l}\text { Caring } \\
\text { 37 References / 30 } \\
\text { Sources }\end{array}$ & $\begin{array}{l}\text { Demonstrates concern related to the general wellbeing of followers, and } \\
\text { taking steps to improve individual followers' life / situations. }\end{array}$ \\
\hline $\begin{array}{l}\text { Objective / } \\
\text { Pragmatic } \\
\text { 37 References / 27 } \\
\text { Sources }\end{array}$ & $\begin{array}{l}\text { Make decisions based on objective fact and merit of the data available } \\
\text { in the situation. }\end{array}$ \\
\hline $\begin{array}{l}\text { Professional / } \\
\text { Technically } \\
\text { Knowledgeable } \\
\text { 16 References / 14 } \\
\text { Sources }\end{array}$ & $\begin{array}{l}\text { Possesses and demonstrates a proven technical background and } \\
\text { professional approach when leading and conducting oneself with } \\
\text { seniors and subordinates. }\end{array}$ \\
\hline $\begin{array}{l}\text { Accountable } \\
\text { 31 References / 22 } \\
\text { Sources }\end{array}$ & $\begin{array}{l}\text { Publicly taking ownership and responsibility over their own and their } \\
\text { followers domains and areas of impact (inclusive of holding follower } \\
\text { and stakeholders responsible for their areas of domain but not in public } \\
\text { forums where they may be blamed - leader accepts }\end{array}$ \\
\hline $\begin{array}{l}\text { Discipline } \\
\text { 34 References / 25 } \\
\text { Sources }\end{array}$ & $\begin{array}{l}\text { Focus and determination on achieving specific goals - focus on output - } \\
\text { while being 'strict' with work and responsibilities, both personally and } \\
\text { for those associated with them. }\end{array}$ \\
\hline $\begin{array}{l}\text { Leading by } \\
\text { Example } \\
\text { 15 References / 10 } \\
\text { Sources }\end{array}$ & $\begin{array}{l}\text { Engages in actions to demonstrate appropriate behaviors to be expected } \\
\text { from follower - ('practice what one preaches") }\end{array}$ \\
\hline $\begin{array}{l}\text { Inisionary / } \\
\text { 15 References / 15 } \\
\text { Sources }\end{array}$ & $\begin{array}{l}\text { Being concerned with and have a cohesive view over 'big picture', } \\
\text { where to direct, what to achieve and what methods to use; willing to use } \\
\text { new methods and approaches to achieve the vision. }\end{array}$ \\
\hline
\end{tabular}




\section{Discussion}

At a very basic level, the results of the analysis indicate that the construct leadership is complex to describe in the extreme. Although this study has isolated nine themes of behaviors that stand out in the eyes of participants as characteristic of "good leadership", each theme represents a complex interplay of subtlety and nuance. Interestingly, there seem to be considerable parallels between the clusters of desirable leadership behaviors identified in the current research and the six universal character strengths described by Peterson \& Seligman (2004).

Table 3: Universal Character Strengths Comparison to Findings

Character Strengths [23]

Wisdom: cognitive strength, love of learning, creativity, perspective, curiosity

Courage: emotional strength, perseverance, bravery, honesty
"Good" Leadership Behaviors (Current research)

Innovativeness \& Visionary, Technical Competence and Professional Knowledge

Lead by Example; Discipline; Objective and Pragmatic

Respectful; Caring ; Guiding and Mentoring caring, nurturing

Justice: fairness, impartiality, teamwork Objective \& Pragmatic; Respectful

\section{Temperance: self-Disciplined, prudence,} humility

\section{Transcendence: Awareness of beauty, humor and hope}

Objective \& Pragmatic; Accountable

Many of the themes overlap (elements of caring overlay behaviors associated with respect) and there are many outlier elements occurring with a lower but consistent frequency such that the research team suspects they are more than just incidental to the practice of leadership. Beyond the specifics of behavior, the attitude of the leader also came out in ways that precluded coding as a behavior but clearly resonated with the participants. One underlying theme that stood out to the research team was the reference in the stories to a sense of optimism that good leaders tended to exude. This was demonstrated by their "can do" attitude toward struggles in situations where both information (technical and situational) was lacking but results were required. In some ways this was represented directly in the stories by the phrase "Pioneer Spirit". In terms of the nine themes, the behaviors appear to be divisible across three categories or types as represented in Figure 2.

\begin{tabular}{|c|c|c|}
\hline \multicolumn{3}{|c|}{ GOOD LEADERSHIP CLUSTERS } \\
\hline \hline CLUSTER 1 & CLUSTER 2 & CLUSTER 3 \\
(RESPECTFUL / FAIR, CARING, & (GUIDING / MENTORING, OBJECTIVE / & (ACCOUNTABLE, DISCIPLINE, \\
LEADING BY EXAMPLE) & PRAGMATIC, VISIONARY / INNOVATIVE) & PROFESSIONAL/TECHNICAL \\
\hline
\end{tabular}

Figure 2: Behavioral Clusters of Good Leadership

The first cluster consists of those behaviors that appear to be externally focused with the intent of having a positive impact at an emotional level on those being led (Respectful/Fair, Caring, Leading by Example). The second cluster consists of those behaviors equally externally focused whose intent it was to further the direct effectiveness of the business itself (Guiding/Mentoring, Objective/Pragmatic, Visionary/Innovative). The third group is differentiated by a more internally 
focused sense of self-modeling by the leader themselves (Accountable, Discipline, and Demonstrating Professional/Technical Knowledge).

The substance and nuances identified in the Chinese stories point more towards a preponderance of 'transformational' behaviors among Chinese leaders. From a Western theoretical perspective, such leadership focuses on transforming followers' motivational state to focus on higher level needs such as self-actualization as described by Maslow's hierarchy of needs. Such observations imply the need for further study exploring the link of leadership to character and the relationship to the notion of transformational leadership as a core descriptor of the necessary Chinese characteristics of leadership required to inspire, motivate and build capability in the follower.

As a final comment related to this study and its operating environment, the study team would like to note the operating environment as a potentially mitigating factor in the factors associated with "Professional / Technically Knowledgeable Behaviors". The petrochemical working environment is not benign on the best of days. The expression "We don't make cookies here", as noted by one of the senior managers, speaks volumes to the risky operating conditions that apply to all petrochemical plants anywhere in the world. In such environments, leaders who bring strong technical and professional skills are highly recognized - these are the people who may save lives and avert operational disasters. With this in mind, the actual operating environment may have influenced the nomination of this particular set of behaviors as core to "good leadership" in China. It would be useful to examine perceptions of leadership in sectors and organizations where operating conditions were less critical to safety to establish whether this particular set of leadership behaviors is nominated as a critical element of the leadership package.

\section{Conclusion}

Good leadership cannot be reduced to a list of behaviors or a set of provisions for action on the part of any would-be leader. In some ways, the development of such a "checklist" for emulation by would-be leaders could imply that leadership is purely transactional, with the core being essentially behavioral in nature. The stories on which this study is based point to a much deeper attitudinal mindset of the "good leaders" nominated - a spirit of devotion to both fellow worker and the mission of the organization that guides and results in a particular set of behaviors. Recent literature on character points in the direction of a necessary internal mindset that is a key differentiating factor in true leadership. [24] It enables leadership behavior to happen in a natural and unforced manner as opposed to some conscious adherence to a "script" on the part of the true leader. The stories analyzed in this study clearly imply that the leadership behaviors on the part of the individuals nominated were essential elements of who they were - part of their leadership character - as opposed to a consciously adopted persona.

On the other hand, the fundamentals of good leadership can be observed in the actions of those who do possess those inner qualities of the leader distinguishing them from their fellow managers and workers. The task of this study has been to capture the thoughts and memories of experiences of good leader behavior of a small sample of Chinese workers and managers in one of China's largest SOEs. Through the compilation of those observations and the analysis of their content, this study has developed a list of behavioral themes representing some of the important actions inspiring both respect and allegiance among followers in a Chinese SOE context. The journey to this list has resulted in many inspiring conversations with participants. Those conversations and their subsequent analysis also resulted in a renewed appreciation of the significance and impact of good leadership on the health and overall effectiveness of the human organization in China and, by implication, in organizations in general.

\section{References}

[1] Ling, W., Chia, R., Fang, L. 2000.Chinese Implicit Leadership Theory The Journal of Social Psychology, 140(6): 729-739 
[2] Barney, J. B., \& Zhang, S. (2009). The future of Chinese management research: A theory of Chinese management versus a Chinese theory of management. Management and OrganizationReview, 5(1) 15-28.

[3] Cheng, B. S., Wang, A. C., \& Huang, M. P. (2009). The road more popular versus the road less travelled: an 'insider's perspective of advancing Chinese management research. Management and Organization Review, 5\(1), 91 - 105.

[4] Miles, M. and Wang, D. 2001. Leadership in the Land of the Dragon. Paper presented at the $4^{\text {th }}$ International Conference on Leadership, Xian, May, 2001.

[5] Wang, D.S. \& Hsieh, C.C. 2013. The effect of authentic leadership on employee trust and employee engagement. Social Behavior and Personality, 41(4): 613-624.

[6] Fernandez, J.A. 2004. The gentleman's code of Confucius: Leadership by values. Organizational Dynamics, 33: 21-33.

[7] Crossan, M., Mazutis, D., Seijts, G., and Gantz, J. 2013. Developing Leadership Character in Business Organizations. Academy of Management Learning \& Education, 12 (2): 285-305.

[8] Tsui, A. S., Wang, H., Xin, K., Zhang, L., \& Fu, P. P. 2004. "Let a thousand flowers bloom": Variation of leadership styles among Chinese CEOs. Organizational Dynamics, 33, 5-20.

[9] Tsui, A. S., Wang, H., Xin, K., Zhang, L., \& Fu, P. P. 2004. "Let a thousand flowers bloom": Variation of leadership styles among Chinese CEOs. Organizational Dynamics, 33, 5-20.

[10] Tsui, A. S., Wang, H., Xin, K., Zhang, L., \& Fu, P. P. 2004. "Let a thousand flowers bloom": Variation of leadership styles among Chinese CEOs. Organizational Dynamics, 33, 5-20.

[11] Fernandez, J.A. 2004. The gentleman's code of Confucius: Leadership by values. Organizational Dynamics, 33: 21

[12] Lin, C.C. 2008. Demystifying the chameleonic nature of Chinese leadership. Journal of Leadership \& Organisational Studies, (14(4): 303-321.

[13] Sheh, S.W. 2010. Confucianism and Chinese leadership. Chinese Management Studies, 4(3): 280-285.

[14] Handy, C. 1995. Trust and the virtual organisation. Harvard Business Review, 73(3): 40-50.

[15] Chen, H.Y. \& Kao, H.S. 2009. Chinese paternalistic leadership and non-Chinese subordinates' psychological health. The International Journal of Human Resource Management, Vol.20(12): 2533-2546

[16] Farh, J.L., and Cheng, B.S. 2000. A cultural analysis of paternalistic leadership in Chinese Organizations. In Li J.T. Tsui, A.S. \& Weldon, E. (eds) Management and Organizations in the Chinese Context, London: Macmillan: 94-127.

[17] Hofstede, G. \& Hofstede, G.J. 2004, Culture and Organizations: Software of the Mind. New York: McGraw-Hill.

[18] Cheng, B.S., Chou, L.F., and Farh, J.L. (2000), 'A Triad Model of Paternalistic Leadership: The Constructs and Measurement, Indigenous Psychological Research in Chinese Societies, 14: 3-64 (in Chinese).

[19] McElhatton, E. \& Jackson, B. 2012. Paradox in harmony: Formulating a Chinese model of leadership. Leadership, (8)4: 441-481.

[20] Westwood, R. 1997. Harmony and Patriarchy: The cultural basis for paternalistic Headship among the overseas Chinese. Organization Studies, 18 (3): 445-480. 
[21] Sheh, S.W. 2010. Confucianism and Chinese leadership. Chinese Management Studies, 4(3): 280-285.

[22] Shalhoop, J.H. \& Sanger, M.R. 2012. Understanding leadership in China: leadership profiles of state-owned enterprises, multinational corporations, and major economic trading partners. In W. Mobley \& (ed.) Advances in Global Leadership: 321-348.

[23] Peterson, C. \& Seligman, M.E.P. 004. The Via Classification of Character Strengths. Retrieved from http://www.viacharacter.org/www/en-us/viainstitute/classification.aspx

[24] Wu, M. \& Wang, J. 2012. Developing a charismatic leadership model for Chinese organizations: the mediating role of loyalty to supervisors. The International Journal of Human Resource Management, 23(19): 4069 - 4084. 